\title{
Ethics of complementary medicine: practical issues
}

\author{
Edzard Ernst
}

\author{
ABSTRACT \\ Complementary medicine is popular, yet ethical issues \\ are rarely discussed. Misleading information, informed \\ consent, publishing, and confidentiality are discussed \\ in the light of medical ethics. The message that \\ emerges is that, in complementary medicine, ethical \\ issues are neglected and violated on a daily basis. \\ Keywords \\ complementary medicine; confidentiality; ethics; \\ informed consent.
}

\section{INTRODUCTION}

Several articles have been written about ethical problems related to complementary medicine, such as those by Ernst, ${ }^{1}$ Kerridge and McPhee, ${ }^{2}$ and Miller et al. ${ }^{3}$ These articles address ethics in the abstract; discussions that focus on practical day-to-day issues are largely missing. This article is aimed at filling the gap by alerting readers to 'real-life' ethical problems in the area of this increasingly popular form of health care.

\section{MISLEADING PATIENTS}

Misleading patients or consumers is unquestionably wrong and can be unethical. Yet, in complementary medicine, this is precisely what happens on a daily basis. Misinformation is extremely widespread but, for the purpose of this article, only a few recent examples are provided.

A survey of promotional leaflets distributed by US and Canadian professional chiropractic organisations showed that all of those sampled claim chiropractic services that 'have not been scientifically validated'. ${ }^{4}$

E Ernst, MD, PhD, FRCP, FRCPEd, professor of complementary medicine, Peninsula Medical School, Universities of Exeter and Plymouth, Exeter.

Address for correspondence

Edzard Ernst, professor of Complementary Medicine, Peninsula Medical School, Universities of Exeter and Plymouth, 25 Victoria Park Road, Exeter EX2 4NT. E-mail: edzard.ernst@pms.ac.uk

Submitted: 2 September 2008; Editor's response: 27 October 2008; final acceptance: 13 November 2008.

(c)British Journal of General Practice

This article was originally online first on 11 June 2009. Cite this article as: Br J Gen Pract 2009; 59: 517-519. Advance online publication. DOI: 10.3399/bjgp09X453404
The authors concluded that this 'reinforces an image of the chiropractic profession as functioning outside the boundaries of scientific behaviour'. ${ }^{4}$

The ethical code of The Royal Pharmaceutical Society of Great Britain informs UK pharmacists that they 'must assist patients in making informed decisions by providing them with necessary and relevant information' when purchasing homeopathic medicines, ${ }^{5}$ yet UK pharmacies distribute misleading promotional material that fails to inform customers that homeopathy is biologically implausible and not supported by convincing data on clinical effectiveness. ${ }^{6}$

The Code of Ethics and Practice of the UK Society of Homeopaths (the professional organisation of British non-doctor homeopaths) states that 'all speculative theories will be stated as such and clearly distinguished', ', yet the website of that society (www.homeopathy-soh.org) is full of speculative theories about the mode of action of homeopathic remedies without the slightest attempt to differentiate between fact and fiction.

The code of ethics of chiropractors of Britain and most other nations make it clear that chiropractors must not use the title 'doctor' such that clients might get the impression they are registered medical practitioners. ${ }^{8}$ However, there is much evidence that the majority of UK chiropractors do precisely that., ${ }^{9,10}$ In addition, a recent survey from New Zealand found that $82 \%$ of chiropractors in that country use the title 'doctor', ${ }^{11}$ a practice that was called 'legally dubious' by the Medical Council of New Zealand.12

\section{INFORMED CONSENT}

Informed consent is an essential prerequisite for both research and clinical practice. Yet there is much anecdotal evidence that many practitioners of complementary medicine fail to obtain informed consent before treating a patient. For instance, in January 2003 the UK General Medical Council (GMC) dismissed a medical homeopath from the medical register, the main reason being that she had not obtained informed consent from her patients before administering homeopathic and other complementary treatments. ${ }^{13}$

British chiropractors recently published a survey of 150 practising chiropractors. Of those who responded, $25 \%$ reported not informing their patients of physical 


\section{How this fits in}

Adequate ethical standards are an essential prerequisite for medical research in any area. This article shows that complementary medicine seems to be an

important exception to this rule. These issues urgently need to be addressed to ensure that complementary medicine complies with the same standards as the rest of health care. often be powerful. The vast majority of complementary medicine research is currently being performed by enthusiasts who aim to prove that their therapy is effective. This can constitute a conflict of interest that might be as influential as a financial conflict, yet it is hardly ever disclosed in publications.

\section{CONFIDENTIALITY}

The UK GMC, along with virtually all other healthcare organisations worldwide, stipulates confidentiality as an essential ethical obligation that can only be breached in certain, well-defined circumstances. ${ }^{21}$ Patients consider confidentiality to be crucial; if anything, they believe it is more important than doctors do. ${ }^{22}$ To the best of the author's knowledge, there is no systematic research into the question as to how rigorously complementary practitioners adhere to confidentiality. Anecdotally, the impression is that breaches occur frequently.

\section{COMMENT}

Considering the currently widespread use of complementary medicine, it is remarkable how rarely the ethical implications of this area of health care are being discussed. Many practitioners receive little or no ethical training during their education. Even the most voluminous standard texts, like the 1500-page Textbook of Natural Medicine, do not include a chapter on medical ethics. ${ }^{23}$ As a consequence, important issues continue to be neglected, ethical guidelines are violated, little research is being done, and crucial questions remain unanswered. It is time to change this deplorable situation.

\section{Competing interests}

The author has stated that there are none.

\section{Discuss this article}

Contribute and read comments about this article on the Discussion Forum: http://www.rcgp.org.uk/bjgp-discuss addicts. ${ }^{18}$ The trial participants were from a 'mandatory drug treatment centre' and no informed consent was sought for the purpose of that study.

\section{PUBLISHING}

Using a systematic comparison of published articles, it was attempted to assess whether differences exist between the reporting of ethical aspects of clinical trials of complementary and conventional medicine..$^{19}$ The results suggested that the former studies reported ethical approval less frequently. The situation was similar when the frequencies of disclosing conflicts of interest and sponsorship were compared.

Conflicts of interest can be 'personal, professional or financial; and they can be actual (do influence judgement) or potential (could affect judgement)'. ${ }^{20}$ In complementary medicine research, financial interests are usually far less pertinent than in pharmacological research, but personal and professional influences can

\section{REFERENCES}

1. Ernst E. The ethics of complementary medicine. J Med Ethics 1996; 22(4): 197-198.

2. Kerridge $\mathrm{IH}, \mathrm{McPhee} J \mathrm{~J}$. Ethical and legal issues at the interface of complementary and conventional medicine. Med J Aust 2004; 181(3): 164-166.

3. Miller FG, Emanuel EJ, Rosenstein DL, Straus SE. Ethical issues concerning research in complementary and alternative medicine. JAMA 2004; 291(5): 599-604.

4. Grod JP, Sikorski D, Keating JC. Unsubstantiated claims in patient brochures from the largest state, provincial, and national chiropractic associations and research agencies. J Manipulative Physiol Ther 2001; 24(8): $514-519$

5. Royal Pharmaceutical Society of Great Britain. Code of ethics for pharmacist and pharmacy technicians. London: Royal Pharmaceutical Society of Great Britain, 2007. http://www.rpsgb.org.uk/pdfs/coeppt.pdf (accessed 21 Apr 2009).

6. Ernst E. Is it ethical for pharmacists to sell unproven or disproven medicines? Pharm J 2008; 281: 75.

7. The Society of Homeopaths. Code of ethics and practice. Northampton: The Society of Homeopaths, 2004. http://www.homeopathysoh.org/about-homeopathy/documents/CodeofEthicsApr04.pdf (accessed 21 Apr 2009).

8. General Chiropractic Council. Code of practice and standard of proficiency. 


\section{COMMENTARY}

\section{Conventional medicine is less than perfect}

Despite the poor evidence base behind many complementary therapies and the lack of proper licensing and governance in many areas, complementary medicine is popular with many. This issue of the BJGP features a discussion of some of the ethical deficits that are allowed to continue in day-to-day practice in the burgeoning complementary medicine field. ${ }^{1}$

Of course, it is trying for conventional medical practitioners to witness the apparently free hand afforded complementary therapists while their own practice is increasingly affected by demands that it must be guided by evidence of clinical- and cost-effectiveness, for continuing assessment of professional standards, and for respect for ethical and data protection constraints. In such circumstances, challenges to ethical standards in complementary medicine are both understandable and inevitable.

But conventional medicine should exercise caution and honesty in its challenges to complementary medicine. While commentators from conventional medicine may rightly feel that they are on firmer ethical ground, it would be wrong to imply that conventional medicine is ethically flawless. One does not have to look to the newsworthy or the dramatic. There are many more workaday instances in which conventional medicine's ethical standards can be challenged.

For example, informed consent is indeed a prerequisite for both medical research and clinical practice. And it may be true that many practitioners of complementary medicine fail to obtain informed consent before treating a patient. But is genuinely informed consent universally sought in the practice of conventional medicine? For example, the prostate specific antigen (PSA) test is widely used as an indicator of presymptomatic prostatic cancer. However, it yields considerable numbers of false positives, leading to unnecessary anxiety and often a potentially risky biopsy, and there remains considerable debate as to whether early detection is beneficial. ${ }^{2}$ Given pressures of time and other factors, it seems unlikely that all patients give genuinely informed consent: the decision is emotionally charged and to give genuinely informed consent patients would require a considerable amount of time and preferably some knowledge of epidemiological principles to discuss it with their doctor. Likewise, conflicts of interest can affect conventional medicine just as they can complementary medicine: while in private practice payment-led incentives to perform tests and procedures might be considered obvious, it might also be argued that the Quality and Outcomes Framework in primary care in the UK promotes payment-led inequity between disease-specific patient groups in general practice. And while little may be known about standards or views relating to confidentiality in complementary medicine, there is clear evidence that concerns exist among patients, clinicians, and practice staff about both accidental and systematic breaches of confidentiality in conventional medicine..$^{3-5}$

It is right that poor ethical standards in complementary medicine should be highlighted and condemned. However, critics comment from a weakened position if they do not equally acknowledge ethical shortfalls in conventional medicine.

\section{Brian S Buckley,}

Cochrane Fellow \& Researcher in Primary Care, National University of Ireland, General Practice, 1 Distillery Road, Galway, Ireland. E-mail: bsbuckley@iol.ie

\section{Provenance}

Commissioned; not peer reviewed

\section{REFERENCES}

1. Ernst E. Ethics of complementary medicine: practical issues. Br J Gen Pract 2009; 59: 517-519. Advance online publication. DOI: 10.3399/bjgp09X453404.

2. Barry MJ. Prostate specific antigen testing for early diagnosis of prostate cancer. N Engl J Med 2001; 344(18): 1373-1377.

3. Carlisle J, Shickle G, Cork M, McDonagh A. Concerns over confidentiality may deter adolescents from consulting their doctors. A qualitative exploration. J Med Ethics 2006; 32: 133-137.

4. Robling MR, Hood K, Houston H, Pill R, et al. Public attitudes towards the use of primary care patient record data in medical research without consent: a qualitative study. J Med Ethics 2004; 30: 104-109.

5. Stone MA, Redsell SA, Ling JT, Hay AD. Sharing patient data: competing demands of privacy, trust and research in primary care. Br J Gen Pract 2005 ; 55: 783-789.

DOI: 10.3399/bjgp09X453558

London: General Chiropractic Council, 2005. http://www.gccuk.org/files/link_file/COPSOP_Dec05_WEB(with_glossary)07Jan09.pdf (accessed 21 Apr 2009).

9. Ernst E. What's in a word? Br J Gen Pract 2003; 53(488): 243-244.

10. Ernst E. The ethics of chiropractic. N Z Med J 2008; 121(1281): 96-97.

11. Gilbey A. Use of inappropriate titles by New Zealand practitioners of acupuncture, chiropractic, and osteopathy. NZ Med J 2008; 121(1278): 15-20.

12. Robb S. Use of title 'Dr' - view of the Medical Council of New Zealand. $N$ Z Med J 2008; 121(1279): 112-123.

13. BBC News. Three-month ban for homeopathy GP. 16 January 2003. http://news.bbc.co.uk/1/hi/england/2666411.stm. (accessed 21 Apr 2009).

14. Langworthy JM, le Fleming C. Consent or submission? The practice of consent within UK chiropractic. J Manipulative Physiol Ther 2005; 28(1): $15-24$.

15. Ernst E. Chiropractic: a critical evaluation. J Pain Symptom Manage 2008; 35(5): 544-562.
16. Caspi O, Holexa J. Lack of standards in informed consent in complementary medicine. Complement Ther Med 2005; 13(2): 123-130.

17. Miller FG, Kaptchuk TJ. Acupuncture trials and informed consent. J Med Ethics 2007; 33(1): 43-44.18.

18. Li M, Chen K, Mo Z. Use of qigong therapy in the detoxification of heroin addicts. Altern Ther Health Med 2002; 8(1): 50-54,56-59.

19. Lim B, Schmidt K, White A, Ernst E. Reporting of ethical standards: differences between complementary and orthodox medicine journals. Wien Klin Wochenschr 2004; 116(14): 500-503.

20. James A, Horton R. The Lancet's policy on conflicts of interest. Lancet 2003; 361: 8-9.

21. General Medical Council. Confidentiality: protecting and providing information. London: GMC, 2000.

22. Jones $\mathrm{C}$. The utilitarian argument for medical confidentiality: a pilot study of patients' views. J Med Ethics 2003; 29(6): 348-352.

23. Pizzorno JE, Murray MT. Textbook of natural medicine. Harcourt: Edinburgh. 2001. 